\title{
Irreversible Inhibitor
}

National Cancer Institute

\section{Source}

National Cancer Institute. Irreversible Inhibitor. NCI Thesaurus. Code C156614.

A class of substances that irreversibly and permanently binds to and decreases the activity of, and/or deactivates a target. 